\title{
Clinical Analysis of Intratympanic Injection of Dexamethasone for Treating Sudden Deafness
}

\author{
Xin $\mathrm{Li}^{1,2}$ \\ Wen-Jing Chen ${ }^{1,2}$ \\ Jia $X^{\prime}{ }^{\prime}$ \\ Hai-Jin $Y i^{1,2}$ \\ Jing-Ying $Y e^{1,2}$ \\ 'Department of Otorhinolaryngology, \\ Beijing Tsinghua Changgung Hospital, \\ Beijing, 102218, People's Republic of \\ China; ${ }^{2}$ School of Clinical Medicine, \\ Tsinghua University, Beijing, 100084, \\ People's Republic of China
}

\begin{abstract}
Introduction: A variety of causes may induce sudden deafness. However, it remains challenging to determine the exact cause in a clinic. There is no standard treatment for this disease due to its unclear etiology.

Objective: The present study aims to investigate the clinical efficacy of the intratympanic injection of dexamethasone for treating sudden deafness.

Methods: A total of 154 patients with sudden deafness were retrospectively analyzed. The evaluation of sudden deafness was based on the AAO-HNS efficacy evaluative criteria. All patients were initially treated within seven days by an intravenous drip of methylprednisolone, vasodilator, and neurotrophic agents. These patients were divided into two groups: the treatment group (91 patients) and the control group (63 patients). Patients in the treatment group were given an intratympanic injection of dexamethasone, while patients in the control group were given conventional vasodilators and neurotrophic treatment.

Results: The effective rate in the treatment group was $47.25 \%$ (43/91 patients), and this was significantly higher than in the control group (14.29\%, 9/63 patients). The adverse reactions in the treatment group included transient pain $(7.69 \%, 7 / 91)$, but there was no vertigo in either group. There was one case of tympanic membrane perforation.

Conclusion: The intratympanic injection of dexamethasone is a better choice for refractory sudden deafness due to its high efficacy and fewer adverse reactions.

Keywords: sudden deafness, dexamethasone, tympanic injection
\end{abstract}

\section{Introduction}

Sudden deafness refers to subjective feelings of hearing impairment that rapidly occur in one or both ears, which can be classified as conductive hearing loss, sensorineural hearing loss, or mixed hearing loss. ${ }^{1}$ This may be induced by various causes, such as infection, tumors, tumor-like lesions, and round window membrane rupture. $^{2}$ A report evaluated the efficacy and safety of high-dose dexamethasone injection in the tympanic cavity in patients with sudden deafness who failed conventional treatment. ${ }^{3}$ They found that high-dose dexamethasone injection into the tympanic cavity is more effective than conventional therapy after one week of treatment. At present, two theories have been widely recognized: viral infection and circulatory disorders of the inner ear. However, there is no standard treatment for this disease due to the unclear etiology. ${ }^{4}$ Thus, the clinical use of antiviral drugs, steroids, vasodilators, neurotrophic agents, and other drugs is an important choice for patients with sudden deafness.

Although the efficacy of systemic corticosteroid treatment for deafness has been confirmed, there are still apparent side effects, such as Cushing's syndrome,
Correspondence: Hai-Jin $\mathrm{Yi}_{\mathrm{i}}$

Department of Otorhinolaryngology

Beijing Tsinghua Changgung Hospital,

No. 168, Litang Road, Changping

District, Beijing, 102218, People's

Republic of China

$\mathrm{Tel} / \mathrm{Fax}+861056118899$

Email yihaijin_med2074@163.com 
induced or aggravated infection, and depression. ${ }^{5-7}$ In addition, the application of systemic steroids remains limited due to the blood-lymph barrier. ${ }^{8}$ Hence, there is an urgent need to identify an agent that can exert better efficacy for sudden deafness with fewer side effects. At present, the intratympanic injection of steroids has been applied to sudden deafness as a remedy therapy, especially for the elderly. ${ }^{9}$ Therefore, the efficacy of the intratympanic injection of dexamethasone was investigated in the present study, and its clinical efficacy was evaluated.

\section{Materials and Methods}

\section{Patients}

A total of 154 patients with sudden deafness seen at the Department of Otorhinolaryngology Head and Neck Surgery, Tsinghua Changgung Hospital, from January 1, 2016, to December 30, 2020, were retrospectively analyzed. This study was conducted in accordance with the Declaration of Helsinki. The Ethics in Research Committee of Tsinghua Changgung Hospital approved the present study. All patients signed written informed consent.

The sudden deafness was evaluated according to the criteria of the American Academy of OtolaryngologyHead and Neck Surgery (AAO-HNS). ${ }^{10}$ Patients diagnosed with sudden deafness for the first time and who had not received any related treatment before admission (duration $\leq 7$ days) were included. Patients with surgical contraindications and autoimmune diseases or patients who had any other signs or symptoms of diabetes or hypertension were excluded from this study.

\section{Treatment}

The patients were divided into two groups based on their choice of treatment: the treatment group (91 patients) and the control group (63 patients). All patients had refractory sudden deafness and were not cured after conventional intravenous administration. Both groups received an intravenous drip of $40 \mathrm{mg}$ of methylprednisolone and $87.5 \mathrm{mg}$ of ginaton for one week. The treatment group was given a $0.8 \mathrm{~mL}$ intratympanic injection of dexamethasone $(5 \mathrm{mg} /$ $\mathrm{mL}$ ). The control group was given methylprednisolone and ginaton treatments only.

The diseased ear was upwards at the supine position, and iodophor was used for disinfection of the external auditory canal. Then, tetracaine was used for surface anesthesia of the tympanic membrane, and a gelatin sponge was inserted into

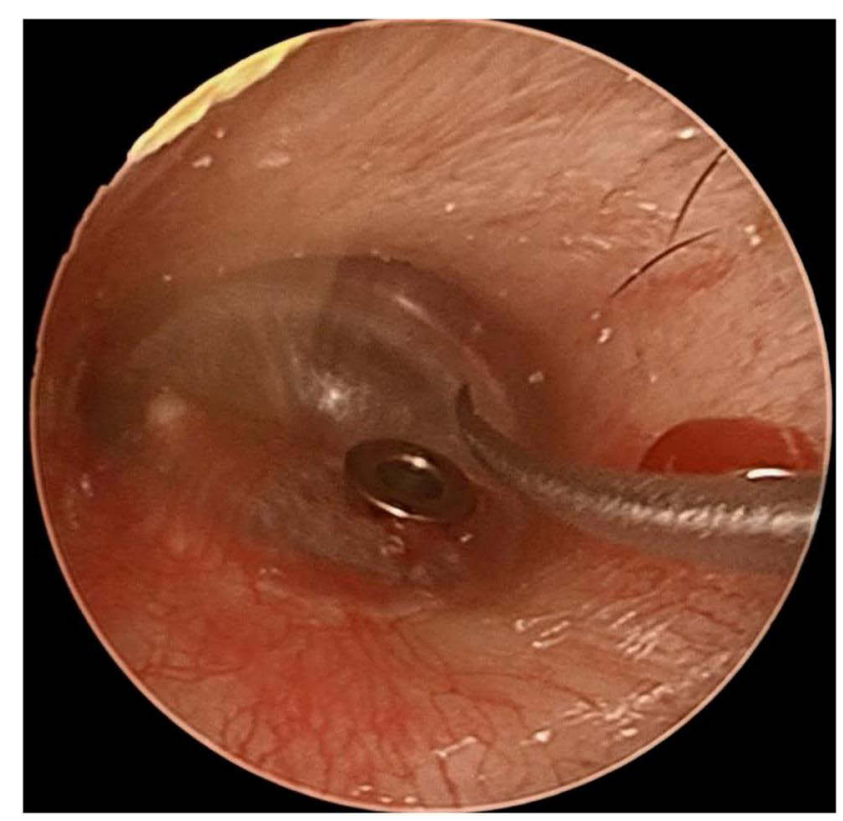

Figure I Anterior inferior quadrant of tympanic membrane.

the middle cavity (Figures 1 and 2). The grommet was inserted at the tympanic membrane, and $1 \mathrm{mg}$ of dexamethasone sodium phosphate was injected and infused into the tympanic cavity. Dexamethasone was chosen because a previous meta-analysis reported that the use of dexamethasone yielded better outcomes than the use of methylprednisolone. ${ }^{11}$ The ear was kept upward. The

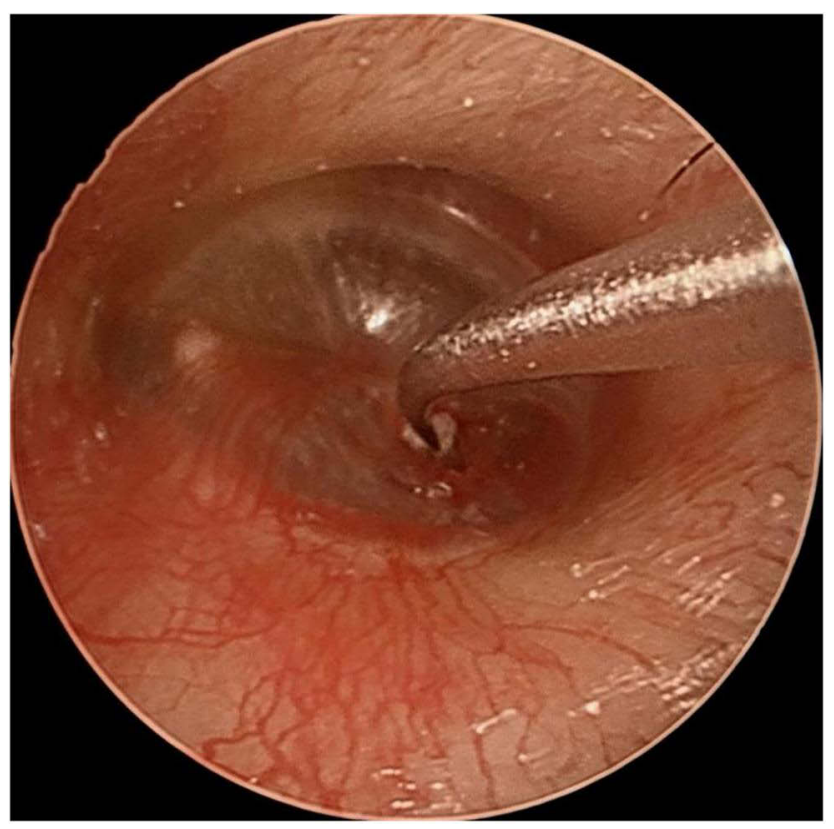

Figure 2 Intraoperative gelatin sponge. 
intratympanic injection of dexamethasone was performed once every four days, for a total of four times.

\section{Evaluation Standard}

After the treatment, the clinical response rate, hearing thresholds, and adverse reactions were compared between the two groups. The hearing thresholds were assessed by the same physician and an improvement of $>10 \mathrm{~dB}$ in thresholds were considered effective.

\section{Statistical Analysis}

SAS 9.4 software was used for the statistical analysis. Numerical data were compared using paired $t$-test or nonparametric Mann-Whitney U rank-sum. The chi-square test analyzed the categorical data. $P<0.05$ was considered statistically significant.

\section{Results}

\section{Gender and Age of Patients}

The present study retrospectively analyzed the treatment efficacy of 154 patients with sudden deafness. The average age of patients in the treatment group $(n=91)$ was $51.23 \pm$ 15.93 years, and the control group $(n=63)$ was $51.38 \pm$ 14.59 years. There was no significant difference in gender or age between the treatment and control groups (Table 1).

\section{Outcomes of Patients}

The effective rate in the treatment group was $47.25 \%$ (43/ 91 patients). The effective rate in the control group was $14.29 \%$ (9/63 patients) (Table 2).

Table I Basic Information of the Two Groups of Patients

\begin{tabular}{|l|l|c|c|c|}
\hline Variable & & $\begin{array}{c}\text { Control } \\
\text { Group }\end{array}$ & $\begin{array}{c}\text { Treatment } \\
\text { Group }\end{array}$ & $P$ \\
\hline Age & & $51.38 \pm 14.59$ & $51.23 \pm 15.93$ & 0.68 \\
\hline \multirow{2}{*}{ Gender } & Male & $27(42.86)$ & $44(48.35)$ & 0.83 \\
\cline { 2 - 5 } & Female & $36(57.14)$ & $47(51.65)$ & \\
\hline
\end{tabular}

\section{Hearing Thresholds of the Two Groups Before and After Treatment}

The air-conduction hearing thresholds at frequencies of 125, 250, 500, 1000, 2000, 4000, and $8000 \mathrm{~Hz}$ were evaluated before and after treatment. The results revealed that the hearing thresholds in both groups were significantly lower after treatment than before treatment $(P<$ 0.05 , Tables 3 and 4).

\section{Adverse Reactions of Both Groups}

In the treatment group, there were eight cases with sideeffects: five with transient pain $(8.79 \%, 9 / 91)$, one with tympanic membrane perforation, one with elevated blood glucose, and one with aggravated depression $(1.09 \%, 1 /$ 91). There was no vertigo.

\section{Word Recognition Score (WRS) of Patients in the Two Groups}

The results are presented in Table 5. The WRS was 37.96 \pm 35.31 before the treatment and $52.32 \pm 34.97$ after the treatment, and the difference was statistically significant.

\section{Discussion}

Sudden deafness has become a research hotspot since Deklyn's first report in $1944 .{ }^{12}$ With the development of medical science, some of the possible etiologies for sudden deafness have been investigated by researchers. The primary therapeutic mechanism of this disease is to increase the oxygen supply of the cochlea, which can improve the ischemia and hypoxia of spiral cells, and ultimately increase the metabolism of hair cells, and promote hair cell regeneration and functional recovery, and the inhibition of inflammation and fibrosis processes. ${ }^{13}$

Glucocorticoids have been widely used due to their excellent anti-inflammatory and immunosuppressive effects. At present, glucocorticoids have been mainly applied to treat sudden deafness. The inflammation caused by a viral infection or immune responses of the inner ear can be reduced by glucocorticoids. ${ }^{14}$ Glucocorticoid receptors are widely

Table 2 Efficacy of the Two Groups (n, \%)

\begin{tabular}{|l|c|c|c|c|c|}
\hline Group & $\mathbf{n}$ & Cured Cases(\%) & Effective Cases (\%) & Ineffective Cases (\%) & Total Effective Rate (\%) \\
\hline Treatment group & 91 & $6(6.59)$ & $37(40.64)$ & $48(52.75)$ & 47.25 \\
\hline Control group & 63 & $1(1.59)$ & $8(12.70)$ & $54(85.71)$ & 14.29 \\
\hline
\end{tabular}

Notes: Cured cases: hearing recovering to normal, or up to the level of healthy ears, or up to the level before the disease; Effective cases: hearing increased by $15 \sim 30 \mathrm{~dB}$ on average; Ineffective cases: The average hearing increased less than $15 \mathrm{~dB}$. 
Table 3 Hearing Thresholds of the Treatment Group Before and After Treatment $(n=91)$

\begin{tabular}{|l|c|c|c|c|}
\hline $\begin{array}{l}\text { Air- } \\
\text { Conduction } \\
\text { Frequencies }\end{array}$ & $\begin{array}{c}\text { Hearing } \\
\text { Thresholds } \\
\text { Before } \\
\text { Treatment }\end{array}$ & $\begin{array}{c}\text { Hearing } \\
\text { Thresholds } \\
\text { After } \\
\text { Treatment }\end{array}$ & $\mathbf{t}$ & $\boldsymbol{P}$ \\
\hline $125 \mathrm{~Hz}$ & $59.23 \pm 31.41$ & $18.85 \pm 9.16$ & $4.5 \mathrm{I}$ & 0.0007 \\
$250 \mathrm{~Hz}$ & $54.62 \pm 27.95$ & $12.69 \pm 8.32$ & 5.42 & 0.0002 \\
$500 \mathrm{~Hz}$ & $56.54 \pm 29.82$ & $13.08 \pm 6.30$ & 5.19 & 0.0002 \\
$1000 \mathrm{~Hz}$ & $64.62 \pm 32.30$ & $16.15 \pm 6.18$ & 5.08 & 0.0003 \\
$2000 \mathrm{~Hz}$ & $62.31 \pm 37.06$ & $18.85 \pm 11.02$ & 3.88 & 0.0022 \\
$4000 \mathrm{~Hz}$ & $70.00 \pm 31.49$ & $29.62 \pm 19.09$ & 4.03 & 0.0017 \\
$8000 \mathrm{~Hz}$ & $69.62 \pm 37.16$ & $28.46 \pm 25.61$ & 3.06 & 0.0100 \\
\hline
\end{tabular}

Table 4 Hearing Thresholds of the Control Group Before and After Treatment $(n=63)$

\begin{tabular}{|l|c|c|c|c|}
\hline $\begin{array}{l}\text { Air- } \\
\text { Conduction } \\
\text { Frequencies }\end{array}$ & $\begin{array}{c}\text { Hearing } \\
\text { Thresholds } \\
\text { Before } \\
\text { Treatment }\end{array}$ & $\begin{array}{c}\text { Hearing } \\
\text { Thresholds } \\
\text { After } \\
\text { Treatment }\end{array}$ & $\mathbf{t}$ & $\boldsymbol{P}$ \\
\hline $125 \mathrm{~Hz}$ & $50.16 \pm 30.54$ & $17.50 \pm 10.12$ & 8.60 & 0.0004 \\
$250 \mathrm{~Hz}$ & $48.97 \pm 29.07$ & $13.49 \pm \mid 1.27$ & 9.62 & 0.0006 \\
$500 \mathrm{~Hz}$ & $46.59 \pm 29.40$ & $13.65 \pm|1.5|$ & 4.69 & 0.0003 \\
$1000 \mathrm{~Hz}$ & $46.43 \pm 31.92$ & $16.03 \pm|1.7|$ & 7.58 & 0.0000 \\
$2000 \mathrm{~Hz}$ & $45.71 \pm 31.84$ & $17.06 \pm \mid 4.27$ & 6.87 & 0.0006 \\
$4000 \mathrm{~Hz}$ & $52.14 \pm 32.60$ & $21.98 \pm 19.21$ & 7.11 & 0.0008 \\
$8000 \mathrm{~Hz}$ & $56.35 \pm 32.37$ & $28.41 \pm 23.33$ & 6.37 & 0.0002 \\
\hline
\end{tabular}

Table 5 Word Recognition Score of the Two Group Before and After Treatment

\begin{tabular}{|l|c|c|c|c|c|}
\hline Group & $\mathbf{n}$ & $\begin{array}{c}\text { WRS } \\
(\bar{x} \pm s)\end{array}$ & $\begin{array}{c}\text { Difference } \\
(\bar{x} \pm s)\end{array}$ & $\boldsymbol{t}$ Value & $\boldsymbol{P}$ value \\
\hline $\begin{array}{l}\text { Treatment } \\
\text { group }\end{array}$ & 91 & $\begin{array}{c}37.96 \\
\pm 35.31\end{array}$ & $14.46 \pm 20.45$ & 4.97 & $<0.05$ \\
\hline $\begin{array}{l}\text { Control } \\
\text { group }\end{array}$ & 63 & $\begin{array}{c}52.32 \\
\pm 34.97\end{array}$ & & & \\
\hline
\end{tabular}

distributed in the inner ear. ${ }^{10}$ In addition, dexamethasone treatment affects the protein resynthesis in the inner ear. However, oral or intravenous glucocorticoids may produce many adverse effects, and the use of glucocorticoids is limited for patients with diabetes, severe hypertension, and gastric ulcers. Hence, dexamethasone and methylprednisolone have been widely applied to treat sudden deafness. $\mathrm{Ng}$ et $\mathrm{al}^{9}$ conducted a meta-analytical review and claimed that the efficacy of dexamethasone is significantly better than methylprednisolone in hearing thresholds. However, there are deficient randomized controlled trials on the intratympanic injection of dexamethasone and methylprednisolone for sudden deafness. The intratympanic injection of dexamethasone and methylprednisolone can slowly diffuse to the niches of the window through the application of gelatin, which plays a significant role in the inner ear. Injecting into the gelfoam and placing this in front of the eustachian tube can prevent the medicine from entering the eustachian tube and becoming lost. In addition, the differences and advantages of the dexamethasone intratympanic injection were that it could avoid the perforation caused by repeated puncture and release hormones for a long duration with the gelatin sponge.

According to previous reports, an intratympanic injection may lead to complications, such as tympanic infection, tympanic membrane perforation, further decline of hearing, transient tinnitus, and dizziness. ${ }^{15,16}$ It has been reported that intratympanic steroids can be absorbed into the digestive tract and inevitably accumulated in the body. ${ }^{17}$ Another recent article evaluated the efficacy and safety of intratympanic and intravenous administration of dexamethasone for sudden sensorineural hearing loss. ${ }^{18-20}$ They found that water-sodium retention, dyssomnia, and appetite were more severe in patients treated with intratympanic administration. However, the method performed in the present study prevented repeated puncture injury and reduced discomfort and pain. Transient pain was found in merely $8.79 \%$ of patients who received an intratympanic injection of dexamethasone, while ear fullness, vertigo, and tympanic membrane perforation were not found in any of these patients.

\section{Conclusion}

In summary, the present study revealed that the intratympanic injection of dexamethasone is effective for refractory sudden deafness, and the hearing thresholds of patients significantly improved. In addition, there were fewer side effects.

\section{Disclosure}

None of the authors have any financial disclosure or conflicts of interest.

\section{References}

1. Chandrasekhar SS, Tsai Do BS, Schwartz SR, et al. Clinical practice guideline: sudden hearing loss (Update). Otolaryngol Head Neck Surg. 2019;161:S1-S45. 
2. Li CQ, Li G, Zhang JH, Dong SP, Wang X, Wang N. [Otoendoscopeassisted transtympanic injection for sudden deafness in the elderly] Chin Arch Otolaryngol Head Neck Surg. 2013;20:121-122. Chinese.

3. Li J, Wang J, Su Y, et al. [Efficacy of high dose glucocorticoid in the salvage treatment of sudden deafness]. Lin Chung Er Bi Yan Hou Tou Jing Wai Ke Za Zhi. 2020;34(7):643-646. Chinese. doi:10.13201/j. issn.2096-7993.2020.07.016

4. Attanasio G, Covelli E, Cagnoni L, et al. Does age influence the success of intra-tympanic steroid treatment in idiopathic sudden deafness? Acta Otolaryngol. 2015;135:969-973. doi:10.3109/ 00016489.2015.1060628

5. Cvorovic L, Jovanovic MB, Milutinovic Z, Arsovic N, Djeric D. Randomized prospective trial of hyperbaric oxygen therapy and intratympanic steroid injection as salvage treatment of sudden sensorineural hearing loss. Otol Neurotol. 2013;34:1021-1026. doi:10.1097/MAO.0b013e318297638a

6. Wijaya CS, Lee JJZ, Husain SF, et al. Differentiating medicated patients suffering from major depressive disorder from healthy controls by spot urine measurement of monoamines and steroid hormones. Int $J$ Environ Res Public Health. 2018;15:865. doi:10.3390/ijerph15050865

7. Tsai HT, Hsueh N, Huang CM, Lin HC. Intratympanic steroid injection as a first-line therapy in uremia patients with sudden sensorineural hearing loss. Acta Otolaryngol. 2015;135:786-790. doi:10.3109/00016489.2015.1027413

8. Dispenza F, De Stefano A, Costantino C, Marchese D, Riggio F. Sudden sensorineural hearing loss: results of intratympanic steroids as salvage treatment. Am $J$ Otolaryngol. 2013;34:296-300. doi:10.1016/j.amjoto.2012.12.010

9. Ng JH, Ho RC, Cheong CS, Ng A, Yuen HW, Ngo RY. Intratympanic steroids as a salvage treatment for sudden sensorineural hearing loss? A meta-analysis. Eur Arch Otorhinolaryngol. 2015;272:2777-2782. doi:10.1007/s00405-014-3288-8

10. Yoo MH, Lim WS, Park JH, et al. Simultaneous versus sequential intratympanic steroid treatment for severe-to-profound sudden sensorineural hearing loss. Audiol Neurootol. 2016;21(6):399-405. doi:10.1159/000464095

11. Geng JJ, Duan Y, Zhao CQ. [Study on effect of intratympanic intravenous injection steroid hormones in the treatment of sudden sensorineural hearing loss]. Chin Foreign Med Res. 2015;13:28-30. Chinese.
12. Yu J. [The effect comparison of ear injection and puncture of the ear drum in the treatment of sudden deafness]. China Contin Med Educ. 2016;8:165-166. Chinese.

13. Liu XJ. [Analysis of intratympanic dexamethasone injection treatment for refractory sudden sensorineural hearing loss effect]. China Contin Med Educ. 2015;7:151-152. Chinese.

14. Chee J, Pang KW, Yong JM, Ho RC, Ngo R. Topical versus oral antibiotics, with or without corticosteroids, in the treatment of tympanostomy tube otorrhea. Int $J$ Pediatr Otorhinolaryngol. 2016;86:183-188. doi:10.1016/j.ijporl.2016.05.008

15. Li Y, Tian X, Tu D. [Adolescent treatment of late refractory sensorineural deafness by tympanic intratympanic injection of steroid therapy clinical observation]. Lin Chung Er Bi Yan Hou Tou Jing Wai Ke Za Zhi. 2013;27:47-48. Chinese.

16. Gundogan O, Pinar E, Imre A, Ozturkcan S, Cokmez O, Yigiter AC. Therapeutic efficacy of the combination of intratympanic methylprednisolone and oral steroid for idiopathic sudden deafness. Otolaryngol Head Neck Surg. 2013;149:753-758. doi:10.1177/ 0194599813500754

17. Qiang Q, Wu X, Yang T, Yang C, Sun H. A comparison between systemic and intratympanic steroid therapies as initial therapy for idiopathic sudden sensorineural hearing loss: a meta-analysis. Acta Otolaryngol. 2017;137(6):598-605. doi:10.1080/ 00016489.2016.1260157

18. Huang J, Yang L, Cao X, Wang W. Differences in hearing recovery following intratympanic alone or intravenous dexamethasone with rescue intratympanic steroids for sudden sensorineural hearing loss: a randomised trial. Clin Otolaryngol. 2021;46(3):546-551. doi:10.1111/coa.13706

19. Fu Y, Jing J, Ren T, Zhao H. Intratympanic dexamethasone for managing pregnant women with sudden hearing loss. $J$ Int Med Res. 2019;47(1):377-382. doi:10.1177/0300060518802725

20. Tarkan Ö, Dağkıran M, Sürmelioğlu Ö, et al. Intratympanic methylprednisolone versus dexamethasone for the primary treatment of idiopathic sudden sensorineural hearing loss. J Int Adv Otol. 2018;14(3):451-455. doi:10.5152/iao.2018.4871
International Journal of General Medicine

\section{Publish your work in this journal}

The International Journal of General Medicine is an international, peer-reviewed open-access journal that focuses on general and internal medicine, pathogenesis, epidemiology, diagnosis, monitoring and treatment protocols. The journal is characterized by the rapid reporting of reviews, original research and clinical studies across all disease areas. The manuscript management system is completely online and includes a very quick and fair peer-review system, which is all easy to use. Visit http://www.dovepress.com/ testimonials.php to read real quotes from published authors. 